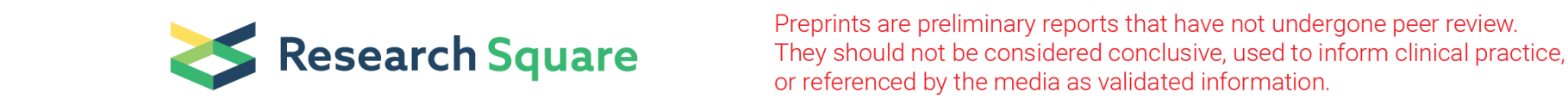

\title{
VaNGuard assay protocol for SARS-CoV-2 detection
}

\author{
Kean Hean Ooi \\ Mengying Mandy Liu \\ Jie Wen Douglas Tay \\ Seok Yee Teo \\ Pornchai Kaewsapsak \\ Shengyang Jin \\ Chun Kiat Lee \\ Jingwen Hou \\ Sebastian Maurer-Stroh \\ Weisi Lin \\ Benedict Yan \\ Gabriel Yan \\ Yong-Gui Gao \\ Meng How Tan ( $\square$ mh.tan@ntu.edu.sg ) \\ https://orcid.org/0000-0003-3627-5586
}

\section{Method Article}

Keywords: CRISPR, COVID-19, diagnostics

Posted Date: May 26th, 2021

DOI: https://doi.org/10.21203/rs.3.pex-1373/v1

License: (c) (1) This work is licensed under a Creative Commons Attribution 4.0 International License. Read Full License 


\section{Abstract}

This protocol presents the Variant Nucleotide Guard (VaNGuard) assay, which is robust towards viral mutations and can be performed on purified RNA or directly on nasopharyngeal (NP) swab samples. The procedure typically comprises three parts, namely sample preparation, RT-LAMP reaction, and Cas12abased detection via fluorescence or lateral flow assay. Sample preparation from NP swabs involves Proteinase $\mathrm{K}$ digestion followed by heat inactivation. Purified RNA or digested NP swab samples are then added as templates into RT-LAMP reactions and incubated at $65^{\circ} \mathrm{C}$ for 22 minutes. Next, enAsCas $12 \mathrm{a}$ and ssDNA-probes are added and the reactions are incubated at $60^{\circ} \mathrm{C}$ for another 5 minutes. End-point fluorescence can be detected by a plate reader or a real-time PCR machine. Alternatively, a lateral flow strip can be inserted into each reaction tube for equipment-free read-out. The VaNGuard assay is a rapid and convenient point-of-care test for SARS-CoV-2 and is applicable to resource poor settings.

\section{Introduction}

\section{Reagents}

CRISPR RNA S2(+4DNA)

rUrArArUrUrUrCrUrArCrUrCrUrUrGrUrArGrArUArCrUrCrCrUrGGrUrGrArUrUrCrUrUrCrUTC (Integrated DNA Technologies)

CRISPR RNA S6(+4DNA)

rUrArArUrUrUrCrUrArCrUrCrUrUrGrUrArGrArUArArArCrCrUrAGrUrGrArUrGrUrUrArArUAC (Integrated DNA Technologies)

FAM-Biotin ssDNA probe: /56-FAM/TTATTATT/3Bio/ (Integrated DNA Technologies)

Cy5-Quencher ssDNA probe: /5Cy5/TTATTATT/3IABKRQ/ (Integrated DNA Technologies)

WarmStart ${ }^{\circledR}$ LAMP Kit (DNA \& RNA) (NEB cat. no. E1700L)

Tango Buffer (10X) (Thermo Scientific, cat. no. BY5)

Q5 ${ }^{\circledR}$ High-Fidelity DNA Polymerase (NEB, cat. no. M0491L)

Proteinase K, Molecular Biology Grade (NEB, cat. no. P8107S)

CoV2-S LAMP Primer F3: TTAATTTAGTGCGTGATCTCC (Integrated DNA Technologies)

CoV2-S LAMP Primer B3: AGCATCTGTAATGGTTCCAT (Integrated DNA Technologies)

CoV2-S LAMP Primer FIP(PM): TGTAAAGCAAGTAAAGTTTGAAACCCTCAGGGTTTTTCGGCT (Integrated DNA Technologies) 
CoV2-S LAMP Primer FIP(tPM-1): TGTAAAGCAAGTAAAGTTTGAAACCCTCAGGGTTTTTCGGC (Integrated DNA Technologies)

CoV2-S LAMP Primer BIP(PM): TGGACAGCTGGTGCTAATAGAAAAGTCCTAGGTTGAAG (Integrated DNA Technologies)

CoV2-S LAMP Primer BIP(tPM-1): TGGACAGCTGGTGCTAATAGAAAAGTCCTAGGTTGAA (Integrated DNA Technologies)

CoV2-S LAMP Primer LB: GCAGCTTATTATGTGGGTTAT (Integrated DNA Technologies)

CoV2-S LAMP Primer LF: GGCAAATCTACCAATGGTTCTAA (Integrated DNA Technologies)

ACTB LAMP Primer F3: GGCATCCACGAAACTACCTT (Integrated DNA Technologies)

ACTB LAMP Primer B3: GCCGATCCACACGGAGTAC (Integrated DNA Technologies)

ACTB LAMP Primer FIP: TGCCGCCAGACAGCACTGTGTGAAGTGTGACGTGGACATC (Integrated DNA Technologies)

ACTB LAMP Primer BIP: TTGCCGACAGGATGCAGAAGGGCGCTCAGGAGGAGCAAT (Integrated DNA Technologies)

ACTB LAMP Primer LF: GGCGTACAGGTCTTTGCG (Integrated DNA Technologies)

ACTB LAMP Primer LB: CCTGGCACCCAGCACAAT (Integrated DNA Technologies)

Milenia ${ }^{\circledR}$ HybriDetect (Milenia Biotec, cat. no. MGHD 1)

\section{Equipment}

- $\quad$ CFX96 Touch $^{\text {TM }}$ Real-Time PCR Detection System (Bio-Rad Laboratories)

- SpectraMax ${ }^{\circledR}$ M5 Microplate Reader (Molecular Devices)

- SimpliAmp Thermal Cycler (Thermo Scientific)

\section{Procedure}

\section{NP swab sample preparation.}

1. $8.3 \mu \mathrm{L}$ of heat-inactivated NP swab samples was added with $1 \mu \mathrm{L}$ of Proteinase $\mathrm{K}$

2. Vortexed for 1 minutes.

3. Heat inactivate Proteinase $\mathrm{K}$ at $95^{\circ} \mathrm{C}$ for 5 minutes. 
4. $2 \mu \mathrm{L}$ of the treated sample is then used for RT-LAMP amplification.

\section{RT-LAMP reaction (with ACTB internal control)}

1. Prepare $10 X$ SARS-CoV2 S primer mix with $22 \mu \mathrm{L}$ of water, $2 \mu \mathrm{L}$ for $\mathrm{F} 3(100 \mu \mathrm{M}), 4 \mu \mathrm{L}$ for $\mathrm{B} 3(100 \mu \mathrm{M})$, $8 \mu \mathrm{L}$ for FIP(PM) $(100 \mu \mathrm{M}), 8 \mu \mathrm{L}$ for BIP(PM) $(100 \mu \mathrm{M}), 8 \mu \mathrm{L}$ for FIP(tPM-1) $(100 \mu \mathrm{M}), 8 \mu \mathrm{L}$ for BIP(tPM-1) $(100 \mu \mathrm{M}), 4 \mu \mathrm{L}$ for $\mathrm{LF}(100 \mu \mathrm{M})$ and $4 \mu \mathrm{L}$ for $\mathrm{LB}(100 \mu \mathrm{M}), 16 \mu \mathrm{L}$ for swarm $\mathrm{F} 1 \mathrm{c}(100 \mu \mathrm{M})$ and $16 \mu \mathrm{L}$ for swarm B1c

2. Prepare $10 X$ ACTB primer mix with $56 \mu \mathrm{L}$ of water, $2 \mu \mathrm{L}$ for $\mathrm{F} 3(100 \mu \mathrm{M}), 2 \mu \mathrm{L}$ for $\mathrm{B} 3(100 \mu \mathrm{M}), 16 \mu \mathrm{L}$ for

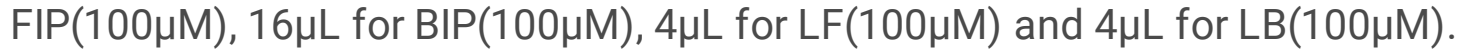

3. Dilute $3 \mu \mathrm{L}$ of Q5 Polymerase at $2 \mathrm{U} / \mu \mathrm{L}$ (NEB) with $99 \mu \mathrm{L}$ of water to $0.06 \mathrm{U} / \mu \mathrm{L}$.

4. Setup RT-LAMP reaction in a $0.2 \mathrm{~mL}$ PCR strip tube with $2.5 \mu \mathrm{L}$ of $10 \mathrm{X}$ SARS-CoV2 $\mathrm{S}$ primer mix, $1.25 \mu \mathrm{L}$ of $10 \mathrm{X}$ ACTB primer mix, $2.5 \mu \mathrm{L}$ of $0.4 \mathrm{M}$ Guanidine $\mathrm{HCl}, 2.5 \mu \mathrm{L}$ of Q5 Polymerase $(0.06 \mathrm{U} / \mu \mathrm{L})$, $1.75 \mu \mathrm{L}$ of water, $0.5 \mu \mathrm{L}$ of LAMP dye and $12.5 \mu \mathrm{L}$ of WarmStart LAMP mastermix.

5. Pipette $2 \mu \mathrm{L}$ of Proteinase K-treated NP swab samples into the assembled reaction in Step 4.

6. Incubate final reaction at $65^{\circ} \mathrm{C}$ for 22 mins. Real time fluorescence can be measure via FAM channel (Ex:450/90, Em:515/30).

\section{quasiOnePot Cas12a reaction (with ACTB internal control)}

1. Pre-complex Cas $12 a$ RNP by mixing $0.75 \mu \mathrm{L}$ of $\mathrm{S} 2(+4 \mathrm{DNA})(5 \mu \mathrm{M}), 0.75 \mu \mathrm{L}$ of $\mathrm{S} 6(+4 \mathrm{DNA})(5 \mu \mathrm{M})$ and $7.5 \mu \mathrm{L}$ of enAsCas $12 \mathrm{a}(100 \mathrm{ng} / \mu \mathrm{L})$

2. Incubate RNP at $37^{\circ} \mathrm{C}$ for at least 15 minutes.

3. Prepare RNP-probe mix with $32 \mu \mathrm{L}$ of water, $7.5 \mu \mathrm{L}$ of $10 \mathrm{X}$ Tango Buffer, $1.5 \mu \mathrm{L}$ of Cy5-Quencher reporter $(10 \mu \mathrm{M})$ and $9 \mu \mathrm{L}$ of complexed RNP.

4. Pipette $50 \mu \mathrm{L}$ of Cas12a-probe mix directly into RT-LAMP products.

5. Incubate reaction mix from Step 4 at $60^{\circ} \mathrm{C}$ for 5 minutes. Fluorescence detection can be done at Ex: 640/Em: 670. 
1. Prepare $10 X$ SARS-CoV2 S primer mix with $22 \mu \mathrm{L}$ of water, $2 \mu \mathrm{L}$ for $\mathrm{F} 3(100 \mu \mathrm{M}), 4 \mu \mathrm{L}$ for $\mathrm{B} 3(100 \mu \mathrm{M})$, $8 \mu \mathrm{L}$ for FIP(PM) $(100 \mu \mathrm{M}), 8 \mu \mathrm{L}$ for BIP(PM) $(100 \mu \mathrm{M}), 8 \mu \mathrm{L}$ for FIP(tPM-1) $(100 \mu \mathrm{M}), 8 \mu \mathrm{L}$ for BIP(tPM-1) $(100 \mu \mathrm{M}), 4 \mu \mathrm{L}$ for $\mathrm{LF}(100 \mu \mathrm{M})$ and $4 \mu \mathrm{L}$ for $\mathrm{LB}(100 \mu \mathrm{M}), 16 \mu \mathrm{L}$ for swarm $\mathrm{F} 1 \mathrm{c}(100 \mu \mathrm{M})$ and $16 \mu \mathrm{L}$ for swarm B1c

2. Dilute $3 \mu \mathrm{L}$ of Q5 Polymerase at $2 \mathrm{U} / \mu \mathrm{L}$ (NEB) with $99 \mu \mathrm{L}$ of water to $0.06 \mathrm{U} / \mu \mathrm{L}$.

3. Setup RT-LAMP reaction in a $0.2 \mathrm{~mL}$ PCR strip tube with $2.5 \mu \mathrm{L}$ of $10 \mathrm{X}$ SARS-CoV2 S primer mix, $2.5 \mu \mathrm{L}$ of $0.4 \mathrm{M}$ Guanidine $\mathrm{HCl}, 2.5 \mu \mathrm{L}$ of Q5 Polymerase $(0.06 \mathrm{U} / \mu \mathrm{L}), 3 \mu \mathrm{L}$ of water and $12.5 \mu \mathrm{L}$ of WarmStart LAMP mastermix.

4. Pipette $2 \mu \mathrm{L}$ of Proteinase K-treated NP swab samples into the assembled reaction in Step 4.

5. Incubate final reaction at $65^{\circ} \mathrm{C}$ for 22 mins.

\section{quasiOnePot Cas12a reaction (Lateral flow readout)}

1. Pre-complex Cas $12 a$ RNP by mixing $0.75 \mu \mathrm{L}$ of $S 2(+4 D N A)(5 \mu \mathrm{M}), 0.75 \mu \mathrm{L}$ of $\mathrm{S} 6(+4 \mathrm{DNA})(5 \mu \mathrm{M})$ and $7.5 \mu \mathrm{L}$ of enAsCas12a $(100 \mathrm{ng} / \mu \mathrm{L})$.

2. Incubate RNP at $37^{\circ} \mathrm{C}$ for 30 minutes.

3. Prepare Cas12a-probe mix with $20 \mu \mathrm{L}$ of water, $7.5 \mu \mathrm{L}$ of $10 \mathrm{X}$ Tango Buffer, $13.5 \mu \mathrm{L}$ of FAM-Biotin reporter(500nM) and $9 \mu \mathrm{L}$ of complexed RNP.

4. Pipette $50 \mu \mathrm{L}$ of RNP-probe mix from Step 3 directly into RT-LAMP products.

5. Incubate reaction mix from Step 4 at $60^{\circ} \mathrm{C}$ for 5 minutes.

6. Pipette $75 \mu \mathrm{L}$ of HybriDetect assay buffer (Milenia Biotec) into the reaction mix from Step 5.

7. Insert dipstick into reaction mix in an upright position.

8. Allow reaction to flow up the flow strip for 2 minutes before inspection. 